\title{
Simulation and Economic Analysis of Solar Thermal Cogeneration System for Production of Heat and Pure Water using Membrane Distillation
}

\author{
Uday Kumar N.T. ${ }^{a, *}$, Andrew Martin ${ }^{b}$ \\ ${ }^{a}$ RAK Research and Innovation Center, American University of Ras Al Khaimah, Ras Al Khaimah, UAE \\ ${ }^{b}$ Department of Energy Technology, KTH Royal Institute of Technology, Stockholm, Sweden
}

\begin{abstract}
In this paper, a novel solar thermal cogeneration (termed as solar combi MD; SCMD) system for production of clean water and domestic hot water is modeled and analyzed for the weather conditions of United Arab Emirates (UAE). The system comprises of solar collectors for production of thermal energy, thermal storage for domestic hot water generation and membrane distillation (MD) modules for clean water production gaining energy through a plate heat exchanger. The performance of cogeneration is analyzed with two different solar collectors used for domestic heating - flat plate collectors (FPC) and evacuated tube collector (ETC). The system is modeled and dynamically simulated using TRNSYS software for optimization of various design parameters like collectors tilt angle, mass flow rate through MD loop, thermal store volume and heat exchanger effectiveness. Cogeneration system efficiencies and collector areas has been determined for optimum conditions. Economic benefits are analyzed for FPC collectors and fuel costs savings compared to individual system operation. Total investment cost of SCMD system for single family application would be around 5000\$ with an impressive payback period of 5.5 years which is $30 \%$ lower than regular SDHW installations.
\end{abstract}

Keywords: Solar Domestic Hot Water, Cogeneration, Membrane Distillation, TRNSYS, Thermal Storage

\section{Introduction}

Desalination has strategic importance in Middle East and North Africa region as a main source of fresh water. Gulf cooperation council (GCC) countries accounts for $57 \%$ of world's desalination capacity out of which one fourth is produced by UAE [1]. The UAE has become leader in implementing alternative methods for creating fresh water resources through desalination. Significant proportion $(25 \%)$ of it is consumed mostly as potable and household water [2]. A recent survey in UAE reveals that only $6 \%$ of people drink tap water due to potential health and safety concerns over tap water [3]. This brings in the big picture of reliance of bottled water by urban population and in fact, UAE stands top as a largest per capita bottled water consumer in the world [4]. The need for sustainable approach to tackle the issue of bottled water has motivated us to develop an in-house water purification unit based on Membrane Distillation technology.

${ }^{*}$ Corresponding author

E-mail: uday.kumar@aurak.ac.ae

(C) 2016 International Association for Sharing Knowledge and Sustainability

DOI: $10.5383 /$ ijtee.11.01.005
MD is a novel process that could be adapted effectively for many water purification applications. Hot-side temperatures below $80^{\circ} \mathrm{C}$ are suitable and this process has been proven ideal for exploiting waste heat or solar thermal resources for small scale applications due to ability of tolerating intermittent and fluctuating conditions [5]. In recent years several bench, pilot and commercial scale solar driven membrane distillation systems with production capacities ranging from 50 1/day to 50 $\mathrm{m} 3 /$ day were developed and tested [6]. Banat et al. developed stand-alone solar desalination systems based on MD to provide potable water in remote areas having abundant solar energy [7]. Spiral wound AGMD modules were developed by Fraunhofer ISE with production capacity of $100,500 \mathrm{~L} /$ day to $10 \mathrm{~m} 3 /$ day $[8,9]$. 
Balnco et al. tested a solar driven multistage flat sheet air gap membrane distillation (AGMD) module with $9 \mathrm{~m} 2$ surface area for desalination with capacity of $0.5 \mathrm{~m} 3 /$ day to $50 \mathrm{~m} 3 /$ day [10]. Solar thermal heating systems are very much common nowadays for fulfilling different domestic and commercial needs. Solar water heating is one of the most popular solar thermal systems and accounts for $80 \%$ of the solar thermal market worldwide. In dry and arid regions like UAE, lack of fresh water resources corresponds to high solar insolation. Theoretically, the average solar insolation in the region of around $600 \mathrm{~W} / \mathrm{m} 2$ is sufficient to run Solar Domestic Hot Water (SDHW) systems at more than 95\% solar fractions. In UAE, hot water is needed during the months from September to May and since the water gets heated to 35 to $450 \mathrm{C}$ in the mains during sunny months, solar thermal systems would be less efficient in summer [11]. A brief research on the design approach of UAE-based suppliers of solar heaters reveals the fact that the majority of SDHW systems $(60 \%)$ is designed for solar fractions less than $75 \%$ [12]. In recent years, the residential building council in UAE promoting shifts to SDHW heaters to regulate energy consumptions and also adapting sustainable strategies for conserving drinkable water for residential population. Therefore, a sustainable integration of water purifier based on MD technology into solar hot water system is proposed in our research study that can produce $1.5-$ $3 \mathrm{l} / \mathrm{hr}$ of pure distillate along with domestic hot water production for a single family dwelling of five in the region [11]. The proposed solar co-production system could maximize the overall solar fraction through co-production of heat and pure water utilizing available energy effectively. Thus, overall thermal performance of system could be increased and additionally acts as source for potable water production. The present paper is focused on dynamic simulation and techno-economic analysis of SCMD system suitable for prescribed application. Hogan et.al. [13], investigated feasibility of solar membrane distillation system using TRNSYS simulation software two decades ago which is well known dynamic simulation tool for academic and commercial purposes. However, no latest research identified using TRNSYS for MD until recently by our own research publications $[14,15]$. Since TRNSYS is an essential tool for analyzing dynamics solar thermal systems, we developed a suitable model for assessment of co-generation operation. Several studies has been presented in literature for simulating solar domestic hot water systems, however present simulation studies through Membrane distillation integration for cogeneration is an unique approach.

\section{System Description}

In order to realize performance dynamics of co-generation of pure water and hot water, a pilot test facility has been designed and installed at RAKRIC, UAE. A regular solar domestic hot water system was procured and installed with increased energy source capacity as shown Fig.1. The plant has been designed to have the flexibility of experimenting at higher hot water and pure water demands. The experimental rig consists of 5 flat plate solar thermal collectors (FPC installed at tilt 35o) from Tisun, Austria and 3 Evacuated tubular collectors (ETC installed at tilt 15o) from Sunda Solar, China. Different arrays were designed and connected in series/parallel combinations in order to operate with varying collector areas. Solar thermal energy is charged to a stratified thermal storage tank of 5201 capacity or during sunshine hours and utilized for DHW with drawl throughout the day according to desired profile. Membrane distillation system was integrated in a flexible manner to operate with heat energy from the thermal storage tank and from direct solar hot water circulation circuit through a stainless steel plate heat exchanger.
All circuits in the test facility were equipped with different measurement and control devices to monitor and control the process. All instrumental data was continuously logged using Advantech Adam data acquisition modules.

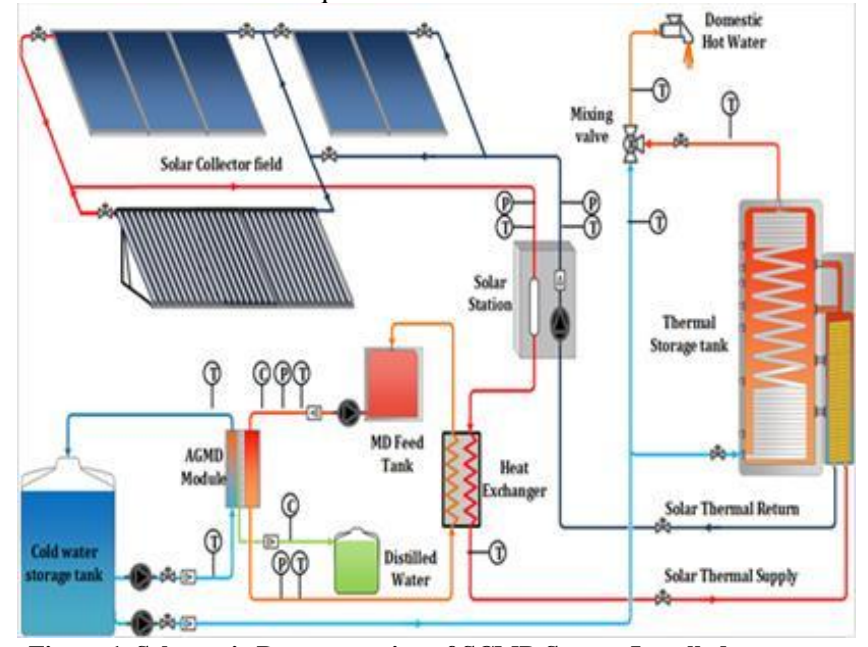

Figure 1. Schematic Representation of SCMD System Installed at RAKRIC

\section{Simulation Model}

TRNSYS dynamic simulation tool is used to simulate the performance of individual and co-generation systems. The basic components like solar collectors, storage tanks, pumps, controllers, heat exchangers, were chosen from TRNSYS library. AGMD is modeled in TRNSYS to analyze both the energy and mass fluxes within the modules, based on inlet hot and cold water temperatures. Post processing involves determining combined solar fraction for co-generation system and also auxiliary heating demand requirement for MD operation.

Flat plate collector (FPC), and Evacuated tube collector (ETC) are simulated using type $1 \mathrm{~b}$ and type 71 models available in the TRNSYS library. The useful heat supplied by the collector is calculated by following equation [10]:

$$
\begin{aligned}
& Q_{u s e f u l}=\dot{m} C_{p}\left(T_{\text {out }}-T_{\text {in }}\right) \\
& \quad=F_{r}\left[I_{r} A(\tau \alpha)-U_{c o l} A_{c o l}\left(T_{i n}-T_{a m b}\right)\right]
\end{aligned}
$$

$F_{r}$ is the heat removal factor of the collector, $\tau \alpha$ is the product of transmittance and absorbance, $A_{c o l}$ is the collector area. The thermal efficiency of the collectors is caiculated using quadratic efficiency curve [23] .

$$
\eta_{\text {Col } T}=a_{o}-a_{1} \frac{\left(T_{a v g}-T_{a m b}\right)}{I_{r}}-a_{2} \frac{\left(T_{a v g}-T_{a m b}\right)^{2}}{I_{r}}
$$

The values of $a_{o}, a_{1}$ and $a_{2}$ are available for any collector tested according to ASHRAE standards. Flat plate collector considered in the study are TISUN FM-S 2.55 model, for which the values of $\eta, a_{1}$ and $a_{2}$ for the FPC are $0.781,3.65 \mathrm{~W} / \mathrm{m}^{2} \mathrm{~K}$ and $0.051 \mathrm{~W} / \mathrm{m}^{2} \mathrm{~K}$ respectively. ETC's are optically non symmetric, so biaxial incidence modifier (IAM) is supplied as separate external file. The values of $a_{o}, a_{1}$ and $a_{2}$ for the SEIDO 1-16 collector type are $0.73,1.5 \mathrm{~W} / \mathrm{m}^{2} \mathrm{~K}$ and $0.0054 \mathrm{~W} / \mathrm{m}^{2} \mathrm{~K}$ respectively. 
The co-generation system includes a thermal storage tank for storing hot water from the collectors loop and it is subjected to thermal stratification.

Type 60c in the TRNSYS library is utilized for the purpose of the hot water storage capacity. The tank is divided into segments and it is assumed that the fluid streams flowing up and down from each node are fully mixed before they enter next segment. The energy balance of the $\mathrm{n}^{\text {th }}$ node model is shown [16]

$$
\begin{aligned}
C P_{t h, n} \frac{d T_{n}}{d t}=\dot{m}_{w, i n} & C_{p}\left(T_{n-1}-T_{n}\right)+\dot{m}_{w, o u t} C_{p}\left(T_{n+1}-T_{n}\right) \\
& -U_{H S} A_{n}\left(T_{n}-T_{a}\right) \\
& +\frac{S_{n} \mu}{\delta}\left(T_{n-1}-2 T_{n}+T_{n+1}\right)
\end{aligned}
$$

Counter flow heat exchanger of Type 91 is used in the model which relies on an effectiveness minimum capacitance approach to modeling a heat exchanger. The maximum possible heat transfer rate is calculated based on the minimum capacity rate fluid and the cold side and hot side fluid inlet temperatures. The model then determines the minimum capacitance side and calculates the heat transfer based on following equation.

$$
\dot{Q}=\varepsilon Q_{\max } \text { where } Q_{\max }=\left(C_{h} \text { or } C_{c}\right)_{\min } *\left(T_{h i}-T_{c i}\right)
$$

Where $C_{C}=m_{C} C_{p c}$ and $C_{h}=m_{h} C_{p h}$.

The outlet temperatures from the heat exchanger are calculated which will provide input to subsequent components, i.e. thermal storage tank and Membrane distillation model for present case.

$$
T_{h o}=\mathrm{T}_{\mathrm{hi}}-\left(\frac{Q_{T}}{C_{h}}\right) \text { and } T_{c o}=\mathrm{T}_{\mathrm{ci}}-\left(\frac{Q_{T}}{C_{c}}\right)
$$

Membrane distillation is simulated based on the Response surface model (RSM) equations developed using factorial design of experiments (DoE) in which distillate flux, MD hot outlet temperatures were calculated as a function inlet hot and cold water temperatures and $\mathrm{MD}$ flow rate.

$$
\begin{gathered}
I_{d}=-9.72+0.117 * T_{\text {Cin }}+0.18 * T_{\text {Hin }}+9.73 * 10^{-3} * V_{f} \\
-6.34 * 10^{-3} * T_{\text {Cin }} * T_{H i n}-3.326 * 10^{-3} * T_{H i n}^{2} \\
T_{\text {Hout }}=2.05+0.189 * T_{\text {Cin }}+0.773 * T_{\text {Hin }}+3.52 * 10^{-3} \\
* V_{f} \\
+1.39 * 10^{-3} * T_{\text {Cin }} * T_{H i n}-2.19 * 10^{-3} * T_{\text {Cin }}^{2}
\end{gathered}
$$

The outlet stream from the MD model is then returned back to heat exchanger for gaining energy from heat source as shown in Fig. 5.1. The heat transfer rate from the exchanger is assumed to be completely utilized for MD process for distillate production with a effectiveness of 0.5 . Control strategies have been implemented for safe operation of solar thermal system. Type $2 \mathrm{~b}$, type controller is used for controlling the solar collector field circulation pump (Type 3) which switches ON/OFF controller based on working fluid temperature. The circulation pump is turned off during two conditions (i) Low radiation (ii) High storage temperature. Flow rates of solar collector loop were fixed according to manufacturer recommendations, $251 / \mathrm{h} . \mathrm{m}^{2}$ for FPC and 301/h.m ${ }^{2}$ for ETC. DHW load profile based on SRCC withdrawal pattern has been modeled using Type 14 time dependent forcing function for water draw. Daily load and desired temperature settings for DHW withdrawal are also provided along with cold inlet temperatures for DHW preparation. Weather data of test location has been supplied as external file. Based on experimental system, loss factors has been considered due to piping.

\section{Results \& Discussion}

As discussed in previous chapters, solar cogeneration system integrating membrane distillation is developed for operation in United Arab Emirates. The simulation is conducted with weather data recorded in RAKRIC for past five years. The cogeneration system is developed with operational flexibility, which allows all the sub systems to operate individually. Integrated operation performance of cogeneration system was analyzed using simulations performed with a simulation time step of $0.25 \mathrm{~min}$ for whole year $(8760 \mathrm{~h})$ and integrated to get monthly or daily results.

\subsection{Performance of individual systems}

In order to determine the validity of the simulation model, individual systems has been simulated first before developing a co-generation model. Solar domestic hot water system (SDHW) installed in UAE conditions which is designed to have a annual solar fraction of 0.85 . SDHW system with $5 \mathrm{~m}^{2}$ FPC area is simulated at a tilt angle of $35^{\circ}$ which maximizes the winter DHW demand fulfillment. It is evident that peak temperatures of TES reaches in month of October and lower in December. For a family of 5 persons in this region, total DHW annual energy consumption would be around $2300 \mathrm{~kW}$ including the auxiliary heating. Annual average collector efficiency of $45 \%$ could be obtained with lowest efficiency in peak summer months.

Direct integration of MD to solar thermal loop enables maximum utilization of absorbed solar heat energy in sstan alone SMD system. Simulation of SMD was performed to achieve a average solar fraction of 0.95 for annual production of 73001 of pure water (201/day). It has been observed that for similar tilt of $35^{\circ}$, four FPC were required to fulfill the demand. However, SMD system produces less than 201/day for almost 6 months due to less driving force but overall annual demand could be fulfilled with excess production in other 6 months. A total of $6900 \mathrm{~kW}$ of heat energy is delivered through the heat exchanger to MD operating at $61 / \mathrm{min}$ of feed flow. Average collector efficiency of $35 \%$ was obtained which is $22 \%$ less than the efficiency when operated for SDHW.

\subsection{Co-generation performance}

Thermal performance of integrated SDHW and SMD system designed to provide required DHW and pure water demand is analyzed through dynamic simulations. Annual simulations has been performed on SCMD system for the existing system configuration of 5FPC (MD flow rate of $3501 / \mathrm{h}$ and heat exchanger effectiveness of 0.5 ) and obtained annual average cogeneration solar fraction $\left(\mathrm{SF}_{\mathrm{Cogen}}\right)$ of 0.9 which is the combined solar fraction of MD and DHW. For the month of October $\mathrm{SF}_{\text {cogen }}$ obtained from simulation was 1.0 and it has been proved from the experimental results discussed previously. DHW tank temperatures are maintained at an average of $77^{\circ} \mathrm{C}$ which makes the SCMD system to operate with DHW solar fraction of 1.0. For the MD system delta $\mathrm{T}$ of $40^{\circ} \mathrm{C}$ was maintained throughout the year with total distillate production of 64001/year. However in order to fulfill the annual demand system parameters have to be optimized which requires a detailed analysis as explained in next section. 


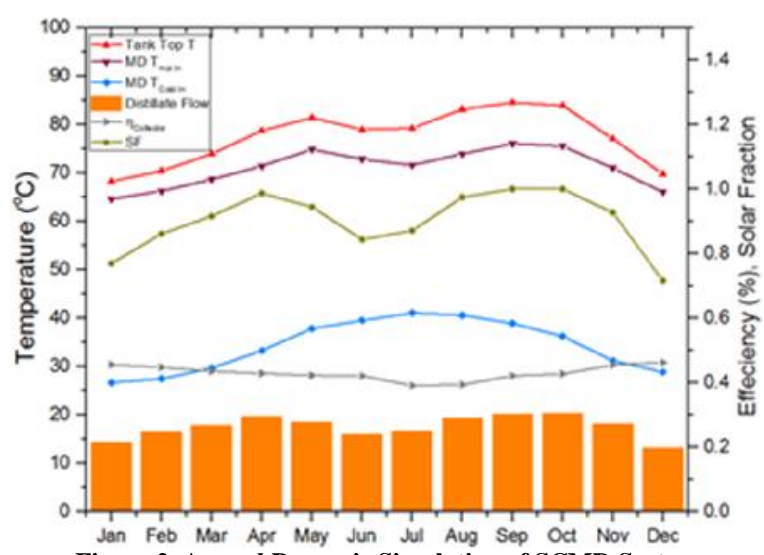

Figure 2. Annual Dynamic Simulation of SCMD System

\subsection{Technical optimization of parameters}

TRNSYS simulations are conducted to optimize the system performance in terms of solar fraction and distillated production. The solar thermal cogeneration system is designed for fulfilling the DHW and pure water demand and the performance of SCMD is analyzed for different collector tilt angles, storage tank capacity, flow rates of heat transfer fluid from MD circuit, and effectiveness of heat exchanger. Based on the optimal parameters, further simulations were carried to obtain optimal collector area. Solar fraction co-generation $\left(\mathrm{SF}_{\mathrm{Cogen}}\right)$ is considered as the indicative performance factor in this study. The performance of co-generation system is evaluated with flat plate collectors and evacuated collectors having similar specifications (Aperture area of $10 \mathrm{~m}^{2}$ ) of experimental installation.

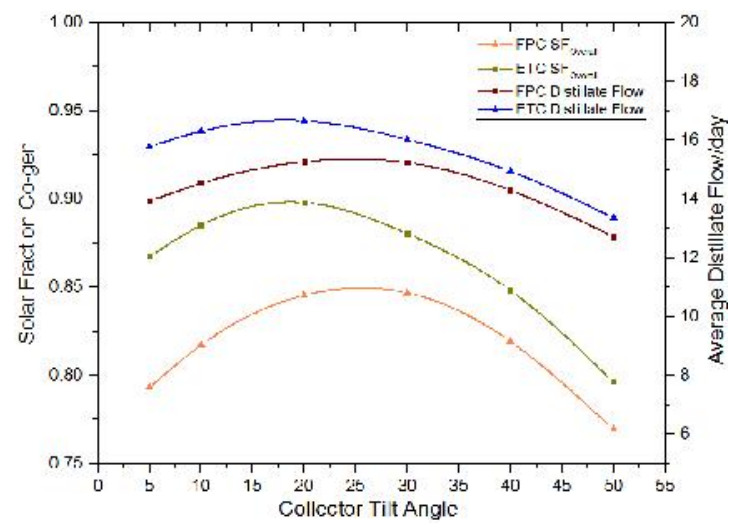

Figure 3 (a). Variation of SCMD Performance with Tilt Angle;

The performance of the SCMD system for two collector types are simulated with different tilt angles with an incremental of $5^{\circ}$ tilt with an objective to increase $\mathrm{SF}_{\mathrm{Cogen}}$. In general tilt angle would be optimum at angles close to latitude of the location (For RAK $25.7^{\circ}$ ) which is clear from the Fig. 3 (a) that $\mathrm{SF}_{\text {Cogen }}$ maximized at a tilt of $25^{\circ}$ for FPC and $20^{\circ}$ for ETC. With increase in collector tilt, distillate production reaches closer to each other for both collector types. This is due to low reduced energy gain from collectors by ETC at higher tilts.
When we consider individual solar fractions for DHW, it was observed that $\mathrm{SF}_{\mathrm{DHW}}$ increased until a tilt of $40^{\circ}$ and reduced after that which shows that DHW requirement during winter is fulfilled better at high tilt angles. ETC collector efficiencies are decreased with tilt whereas an increase is observed for FPC. Therefore considering DHW maximization, a tilt angle of $35^{\circ}$ would provide a balance to the SCMD system with winter optimum production.

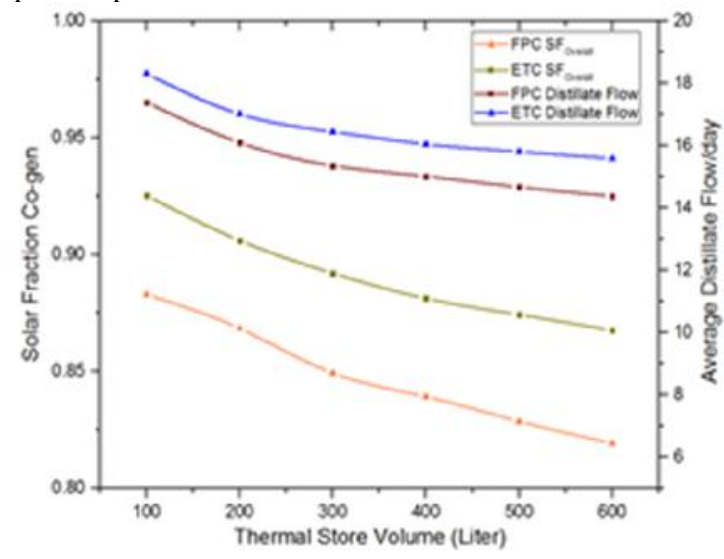

Figure 3 (b). Variation of SCMD Performance with Thermal Storage Volume

Impact in the performance of the SCMD system for various capacities of the storage tank volume is shown in Fig. 3(b). The system is simulated for the storage capacities between 100 to 6001 with an increment of 1001. The SFCogen maximizes at lower storage capacities which are due to increase MD solar fraction. However, DHW solar fraction is low at lower storage volumes and hence optimal volume has to be maintained to increase SFDHW. For DHW withdrawal during night hours storage volume should be sufficient enough and hence an optimal volume of 3001 has been selected for SCMD system. For the same collector aperture areas, ETC has 11-13\% higher solar fractions compared to FPC. Again, this is due to increased collector outlet temperatures from ETC which leads to subsequent increase in MD hot side temperatures. From the above mentioned optimal parameters of $35 \mathrm{o}$ tilt, TES volume of 3001, MD flow rate of 3501/hr and heat exchanger effectiveness of 0.5 , further simulations has been carried to determine optimum collector area required to obtain a minimum SFCogen of 0.95 which might be operated without any auxiliary heaters for UAE region. Objective is also to maximize solar fractions for both MD and DHW operation and the simulation results are plotted as shown in Fig. 5.9 and 5.10.

As shown in Fig. 5.9, when a simple SDHW system with $5.5 \mathrm{~m} 2$ aperture area ( 2 collectors) SFCogen would be around 0.55 and to achieve a solar fraction of near to 1.0, collector area should be increased by $130 \%$ which caters to increase demand by integrating MD into SDHW. Therefore, optimum FPC area requirement for SCMD system would be $12.7 \mathrm{~m} 2$ which is almost equivalent to 5 collectors having an average efficiency of $40 \%$ (which is the average of individual system efficiencies $45 \%$ for SDHW and 35\% for SMD). Also, efficiencies are decreased by $20 \%$ with increased collector area from base level to optimum level. Similarly as shown in Fig. 5.10, for ETC system configuration, $9.3 \mathrm{~m} 2$ aperture area would be required for optimal SCMD operation which is equivalent to 3 collectors having an average efficiency of $56 \%$. 

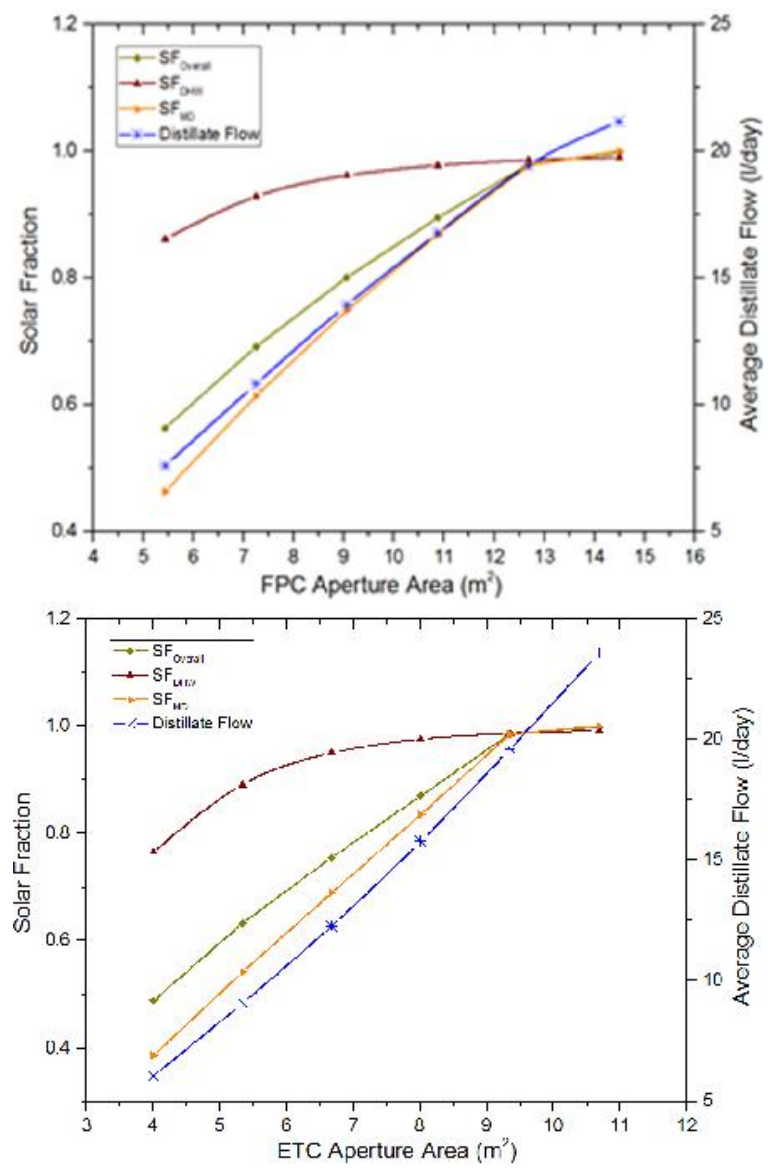

Figure 4. Variation of SCMD Performance with Collector Area (a) FPC, (b) ETC

\subsection{Sensitivity Analysis}

As discussed in earlier section, solar cogeneration system integrated with five solar collectors is optimized to meet the daily demands of pure water and domestic hot water demands of single family household in UAE. Economical benefits of SCMD are analyzed in terms of payback period(PB) and net cumulative saving (NCS) by incorporating fuel inflation rates. Cost of individual components obtained from existing installation suppliers and other parameters are shown in Table 1.

Table. 1. Individual Costs and Benefits

\begin{tabular}{|c|c|c|}
\hline Component & Abbreviation & Value \\
\hline Solar collector & $\begin{array}{l}\text { कobreviation } \\
\bar{C}\end{array}$ & $200 \$ / \mathrm{m}^{2}$ \\
\hline $\begin{array}{l}\text { Membrane } \\
\text { distilltion unit }\end{array}$ & $\begin{array}{l}\overline{\bar{C}}_{S C} \\
\bar{C}^{l, A G M D}\end{array}$ & $250 \$$ /unit \\
\hline $\begin{array}{l}\text { Membrane } \\
\text { replacement }\end{array}$ & $\begin{array}{l}C_{\text {I.AGMD }} \\
C^{K, A G M D}\end{array}$ & 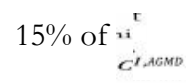 \\
\hline $\begin{array}{l}\text { Plate heat } \\
\text { exchanger }\end{array}$ & $\begin{array}{l}C^{R, A G M D} \\
C^{P H E}\end{array}$ & $\$ 500$ \\
\hline $\begin{array}{l}\text { DHW Thermal } \\
\text { storage tank }\end{array}$ & $\begin{array}{l}c^{p n E} \\
c^{\text {DTS }}\end{array}$ & $\$ 1000$ \\
\hline $\begin{array}{l}\text { MD Thermal } \\
\text { storage tank }\end{array}$ & $\begin{array}{l}C^{\text {DTs }} \\
c^{r s}\end{array}$ & $\$ 250$ \\
\hline
\end{tabular}

\begin{tabular}{|c|c|c|}
\hline Component & Abbreviation & Value \\
\hline Pump & 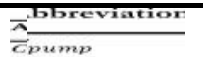 & $881 \mathrm{~W}_{\mathrm{P}}^{0.4}$ \\
\hline Hydraulics & $\begin{array}{l}\vec{C}_{\text {pump }} \\
C_{\text {hyyd }}^{\text {hyd }}\end{array}$ & $\begin{array}{l}0.15^{\overline{\mathrm{x}}} \mathrm{CSC}^{+} \\
0.05^{\mathrm{C} G, A G M D}\end{array}$ \\
\hline Installation cost & $\begin{array}{l}c^{n y a} \\
C^{i n s}\end{array}$ & $\begin{array}{l}5 \% \text { of total } \\
\text { component cost }\end{array}$ \\
\hline $\begin{array}{l}\text { Fuel cost inflation } \\
\text { rate }\end{array}$ & $i^{i n s}$ & $10 \%$ \\
\hline $\begin{array}{l}\text { Lifetime of the } \\
\text { system }\end{array}$ & $\mathrm{N}$ & 20 years \\
\hline Cost of fuel & $\stackrel{R}{C F}$ & $0.12 \$ / \mathrm{kWh}$ \\
\hline $\begin{array}{l}\text { Distilled water } \\
\text { cost }\end{array}$ & $c^{F}$ & $0.08 \$ /$ liter \\
\hline Plant Availability & - & $96 \%$ \\
\hline
\end{tabular}

The major hindrance in any renewable energy driven processes are high initial investment cost, so payback period and net cumulative savings are chosen as economic criteria to evaluate the benefits based on design parameters. In this research work, payback period $(\mathrm{PB})$ is calculated based on time period required to recover initial investment incorporating fuel cost inflation rates. Payback period (PB) and net cumulative saving (NCS) are calculated by [14],

$$
\begin{aligned}
& =\frac{\ln \left[\frac{C_{S}\left(\frac{\left.i_{F}-d\right)}{C_{B}}+1\right]}{\ln \left(\frac{1+i_{F}}{1+d^{2}}\right)}\right.}{P W F=\frac{1}{\left(i_{F}-d\right)}\left(1-\left(\frac{\left(1+i_{F}\right)}{(1+d)}\right)^{N}\right)} \\
& N C S=\left(\left(C_{B}\right) * P W F\right)-C_{S}
\end{aligned}
$$

$C_{S}$ is the initial investment cost for the cogeneration system, $C_{B}$ is annual cost benefits and $i_{F}$ is fuel cost inflation rate. Initial investment includes investment costs of all the components and installation charges of the cogeneration system as shown in equation (8).

$$
\begin{gathered}
C_{S}=C_{S C} A_{S C}+C_{P H E}+C_{H S T}+C_{\text {pump }}+C_{l, A G M D}+C_{R, A G M D} \\
+C_{\text {lns }}+C_{\text {hyd }}+C_{\text {Land }}
\end{gathered}
$$

The total investment cost required for the installation and commissioning of SCMD is $\$ 5000$ with major share (50\%) of investment is accounted for procurement and installation of solar collectors as shown in Fig.5. From literature, a standalone solar MD system have $70-80 \%$ of costs attributed to solar installation [5].

Sensitivity studies on payback period and net cumulative savings (NCS) are conducted with different inflation rates as shown in Fig.6. Payback period varies between 5 and 7 years across different inflation rates for SCMD. Whereas, net cumulative savings without accounting inflation rate lies around $\$ 12,400$ and increases up to 5 times with incorporation of higher inflation rates. At discount rate of 5\%, impressive payback period is obtained for SCMD with 5.5 years at $10 \%$ inflation. SCMD has low payback period compared to all other configurations and high NCS equaling STSMD. 


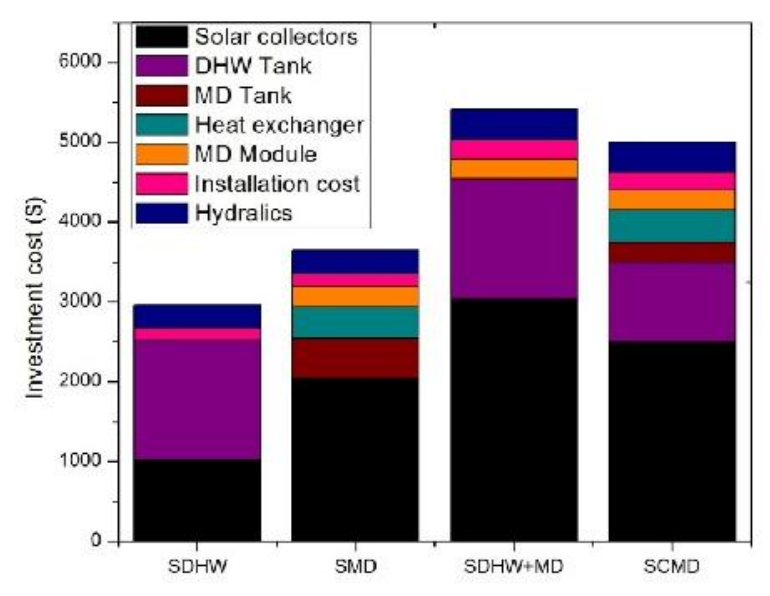

Figure 5. Distribution of Investment Costs for SCMD System
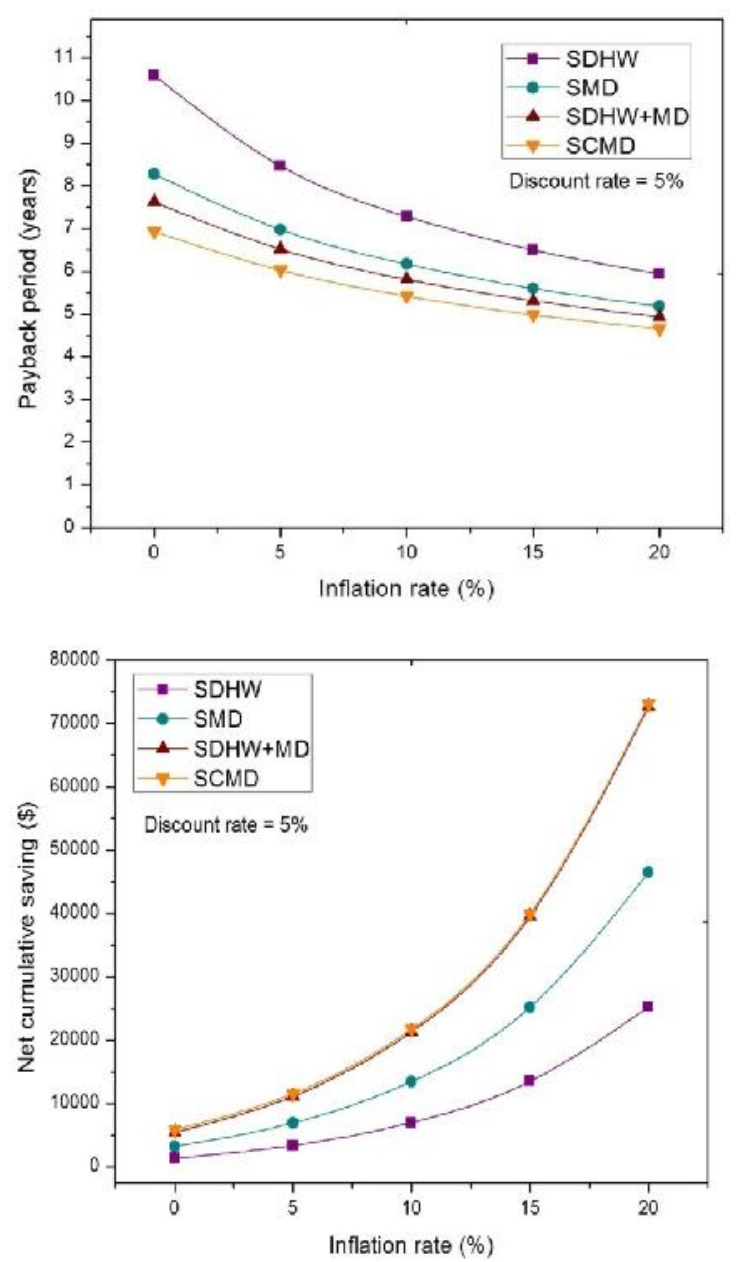

Figure 6. Variation of Payback Period and NCS with Inflation Rate for SCMD and SDHW

An average reduction in PB period of $30 \%$ could be obtained by shifting to SCMD instead of SDHW installation. Similarly NCS could be increase to three fold by adapting SCMD systems.

\section{Concluding Remarks}

A solar thermal cogeneration system integrating membrane distillation is reported and dynamically simulated using TRNSYS. Simulation results are validated with the experimental observations with good agreement. Optimization of the design parameters are conducted for maximizing the energetic performance for two different collector types. Annual system simulation carried out to analyze dynamic behavior using the optimal parametric conditions. 5 FPC and 3 ETC configuration would be sufficient enough for cogeneration system annual demand fulfillment. Collector efficiencies of $40 \%$ were obtained for SCMD systems which is the average efficiency of operation systems individually. Total investment cost of SCMD system for single family application would be around $5000 \$$ which is $68 \%$ more than regular solar hot water installation. Economic analysis indicates a $\mathrm{n}$ impressive payback period of 5.5 years for cogeneration system which is $30 \%$ lower than regular SDHW installations. However, final water production has to be estimated based on post treatment equipment utilized for mineralization or disinfection. Since all the system components were used simultaneously for dual demand fulfillment in SCMD reducing additional components if operated separately, it could be a reliable integration provided MD operated at better thermal efficiencies. Also, for solar-combi MD system significant carbon emissions could be reduced due to equivalent bottle water production and distribution chain which could be determined in future work.

\section{References}

[1] Mezher T, Fath H, Abbas Z, Khaled A. Technoeconomic assessment and environmental impacts of desalination technologies. Desalination 2011; 263266.

[2] http://www.emirates247.com/news/emirates/is-uaetap-water-safe-to-drink-we-ask-experts-2013-08-011.516256 [Accessed on $5^{\text {th }}$ November 2015]

[3] http://www.beveragemarketing.com/ [Accessed on $5^{\text {th }}$ November 2015].

[4] Gleick P H and Cooley H S, Energy implications of bottled water. Environmental Research Letters 2009; 4.

[5] Qtaishat, M.R.; Banat, F. Desalination by solar powered membrane distillation systems. Desalination 2013, 308, 186-197.

[6] Lucy M C, Ludovic D, Jianhua Z, Jun-de L, Mikel D, Juan G, and Stephen G. Advances in Membrane Distillation for Water Desalination and Purification Applications. Water 2013; 5; 94-196.

[7] Banat, F.; Jwaied, N.; Rommel, M.; Koschikowski, J.; Wieghaus, M. Desalination by a "compact smades" autonomous solarpowered membrane distillation unit. Desalination 2007, 217, 29-37.

[8] Koschikowski, J.; Wieghaus, M.; Rommel, M.; Ortin, V.S.; Suarez, B.P.; Betancort Rodríguez, J.R.Experimental investigations on solar driven standalone membrane distillation systems for remote areas. Desalination 2009, 248, 125-131. 
[9] Banat, F.; Jwaied, N. Autonomous membrane distillation pilot plant unit driven solar energy: Experiences and lessons learned. Int. J. Sustain. Water Environ. Syst. 2010, 1, 21-24.

[10] Blanco Gálvez, J.; García-Rodríguez, L.; MartínMateos, I. Seawater desalination by an innovative solar-powered membrane distillation system: The medesol project. Desalination 2009, 246, 567-576.

[11] Kumar U and Martin A. Co-generation of Drinking Water and Domestic Hot Water Using Solar Thermal Integrated Membrane Distillation System, Energy Procedia 2014;61:2666-2669.

[12] http://estidama.upc.gov.ae/estidama-villa-productsdatabase.aspx?lang=en-US [Accessed on 5th November 2015]
[13] P. Hogan, A. Sudjito, G.Fane and G. Morrison. Desalination by solar heated membrane distillation, Desalination 1991;81:81-90

[14] Mohan G, Kumar U, Pokhrel MK, Martin A. A Novel solar thermal polygeneration system for sustainable production of cooling, clean water and domestic hot water in United Arab Emirates: Dynamic simulation and economic evaluation. Applied Energy 2015 (DOI: 10.1016/j.apenergy.2015.10.116)

[15] Mohan G, Dahal S, Kumar U, Martin A, Kayal H. Development of Natural Gas Fired Combined Cycle Plant for Tri-Generation of Power, Cooling and Clean Water Using Waste Heat Recovery: Techno-economic analysis . Energies 2014;7(10):6358-81. 